\title{
Learning And Teaching In Digital Age
}

\author{
Zulhendri' $^{1)}$, Jamaris ${ }^{2 *}$, Solfema ${ }^{3)}$ \\ 1) Program Studi Doktor Ilmu Pendidikan Pascasarjana Universitas Negeri Padang \\ 2,3) Universitas Negeri Padang \\ *Coresponding Author \\ Email : zulhendripoenya@gmail.com
}

\begin{abstract}
The purpose of this study is to find out the use of technology for teaching and learning in digital area. The research method is literature review or literature study, which contains theories relevant to research problems. The result of the use of technology for teaching and learning in digital area are Computer-Based Learning, computer networking, Online learning environment, Social Media and a paradigm shift. Learning in the digital era is complex and dynamic since it involves mix of work, social life and education system that we need to understand alongside the different theories of education and learning
\end{abstract}

Keywords: Learning and teaching, digital area.

\section{INTRODUCTION}

Education is the most serious instrument and is the main focus of each country. The progress of a country is often measured by the level of quality of its education. In the world of education, digitalization will bring very fast progress, namely the emergence of various learning sources and the spread of mass media, especially the internet and electronic media as a source of knowledge and educational center. The impact is teachers/educators are not the only source of knowledge. As a result, students can get knowledge that has not been mastered by the teacher.

Education held in various worlds originally had a unique style and style different characteristics. But over time, these differences more and more eroded. At least developing countries are currently competing competition to catch up with developed countries. There has been a lot of effort influence the models and patterns of education developed by countries around the world. This dynamic can be felt as far as Indonesia, the indications can be seen from the implementation of various service standards in education in Indonesia, starting with ISO standards to other standards.

Progress is a necessity that all nations want to achieve, including Indonesia. The Indonesian nation has gone through various dynamics and is full of sweets bitterness of globalization. The reform movement that has been carried out for more than 20 years has affect many aspects of life in Indonesia. So far, the changes and improvements that have been made have been running and impact on improvement. In terms of quantity, each year the number of students and educational institutions continues to increase. However, from a quality perspective, these improvements not evenly distributed nationally. Inequality and differences in the potential of each region affect the implementation of the educational activity itself. This is 
what causes the progress of education in Indonesia has been slow. When the government is boosting the education sector so that it can be equal to education in developed countries, challenges re-emerge. The old conventional world dominate and become a world culture, has now been eroded and it is not impossible for civilization conventional will disappear. This big change has implications for mindset, activity and power creativity of the world community in general. In the world of education the image of the former teacher considered the most dominant, influential and multi-talent by students will gradually shift. School considered unable to accommodate the needs of students. If this is the case then school especially educators will lose their spirit in the eyes of students. On the other hand, for educators who able to display an adaptive attitude, this momentum will be the best improve the knowledge, insight and skills of students.

Computer theories and beliefs about education will influence strongly the choice and use of different technologies. On the technical side, it is becoming increasingly difficult to classify or categorize technologies, not just because they are changing so quickly, but also because technologies have many different qualities and affordances that change according to the contexts in which they are used. On the pragmatic side, it would be a mistake to focus solely on the pedagogical characteristics of technologies. There are social, organizational, cost and accessibility issues also to be considered.

The selection and use of technologies for teaching and learning is driven as much by context and values and beliefs as by hard scientific evidence or rigorous theory. So there will not be one 'best' framework or model. On the other hand, given the rapidly escalating range of technologies, educators are increasingly caught between technological determinism (inappropriate applications of artificial intelligence, for instance) or the total rejection of technology for teaching because it is so complex. Thus the people need some models to guide their selection and use. According to the background, the formulation of the problem in this journal is the use of technology for teaching and learning in digital area

\section{RESEARCH METHODS}

The research method is literature review or literature study, which contains theories relevant to research problems. The problem in this research is to find out out the use of technology for teaching and learning in digital area. In this section, the concepts and theories used is carried out based on the available literature, especially from articles published in various scientific journals. Literature review serves to build concepts or theories that form the basis of studies in research. Literature review or literature study is an activity that is required in research, especially academic research whose main purpose is to develop theoretical aspects as well as aspects of practical benefits.

\section{RESULTS AND DISCUSSION}

Thomas Friedman (2005) argues that technology, economics, and population growth have created a global economy where competition favors countries with trained workers willing to accept low wages. The science and technology necessary to produce and sell mass-produced goods and services has spread across the globe, and the high-wage economies of developed countries reward those who can do innovative work and punish those who can not. As a result, schools and universities face a new challenge. In the old industrial economies of developed 
nations, graduates who had mastered basic skills in reading, writing, and mathematics were able to find good jobs. But young people in such countries today need to think less like assembly line workers and more like professionals who solve problems that do not have easy answers. Besides, the students make use of digital learning resources to learn on their own (De \& Franco, 2013). In other words, each student has his or her own preferences on how they learn in the web-enhanced environment. Here is the use of technology for teaching and learning in digital area:

\section{Computer-based learning}

In essence the development of programmed learning aims to computerize teaching, by structuring information, testing learners' knowledge, and providing immediate feedback to learners, without human intervention other than in the design of the hardware and software and the selection and loading of content and assessment questions. B.F. Skinner started experimenting with teaching machines that made use of programmed learning in 1954, based on the theory of behaviorism. Skinner's teaching machines were one of the first forms of computer-based learning.

PLATO was a generalized computer assisted instruction system originally developed at the University of Illinois, and, by the late 1970s, comprised several thousand terminals worldwide on nearly a dozen different networked mainframe computers. PLATO was a highly successful system, lasting almost 40 years, and incorporated key on-line concepts: forums, message boards, online testing, e-mail, chat rooms, instant messaging, remote screen sharing, and multi-player games.

Attempts to replicate the teaching process through artificial intelligence (AI) began in the mid-1980s, with a focus initially on teaching arithmetic. Despite large investments of research in AI for teaching over the last 30 years, the results generally have been disappointing. It has proved difficult for machines to cope with the extraordinary variety of ways in which students learn (or fail to learn). Recent developments in cognitive science and neuroscience are being watched closely but at the time of writing the gap is still great between the basic science, and analyzing or predicting specific learning behaviors from the science.

More recently we have seen the development of adaptive learning, which analyses learners' responses then re-directs them to the most appropriate content area, based on their performance. Learning analytics, which also collects data about learner activities and relates them to other data, such as student performance, is a related development.

\section{Computer networking}

In the late 1970s, Murray Turoff and Roxanne Hiltz at the New Jersey Institute of Technology were experimenting with blended learning, using NJIT's internal computer network. They combined classroom teaching with online discussion forums, and termed this 'computer-mediated communication' or CMC (Hiltz and Turoff, 1978). At the University of Guelph in Canada, an off-the-shelf software system called CoSy was developed in the 1980s that allowed for online threaded group discussion forums, a predecessor to today's forums contained in learning management systems. In 1988, the Open University in the United Kingdom offered a course, DT200, that as well as the OU's traditional media of printed texts, television programs and audio-cassettes, also included an online discussion component using CoSy. Since this course had 1,200 registered students, it was one of the earliest 'mass' open online courses. We see then the emerging division between the use of computers for automated or programmed learning, and the use of computer networks to enable students and instructors to communicate with each other. 
The Word Wide Web was formally launched in 1991. The World Wide Web is basically an application running on the Internet that enables 'end-users' to create and link documents, videos or other digital media, without the need for the end-user to transcribe everything into some form of computer code. The first web browser, Mosaic, was made available in 1993. Before the Web, it required lengthy and time-consuming methods to load text, and to find material on the Internet. Several Internet search engines have been developed since 1993, with Google, created in 1999, emerging as one of the primary search engines.

3. Online learning environments

In 1995, the Web enabled the development of the first learning management systems (LMSs), such as WebCT (which later became Blackboard). LMSs provide an online teaching environment, where content can be loaded and organized, as well as providing 'spaces' for learning objectives, student activities, assignment questions, and discussion forums. The first fully online courses (for credit) started to appear in 1995, some using LMSs, others just loading text as PDFs or slides. The materials were mainly text and graphics. LMSs became the main means by which online learning was offered until lecture capture systems arrived around 2008.

By 2008, George Siemens, Stephen Downes and Dave Cormier in Canada were using web technology to create the first 'connectivist' Massive Open Online Course (MOOC), a community of practice that linked webinar presentations and/or blog posts by experts to participants' blogs and tweets, with just over 2,000 enrollments. The courses were open to anyone and had no formal assessment. In 2012, two Stanford University professors launched a lecture-capture based MOOC on artificial intelligence, attracting more than 100,000 students, and since then MOOCs have expanded rapidly around the world.

4. Social media

Social media are really a sub-category of computer technology, but their development deserves a section of its own in the history of educational technology. Social media cover a wide range of different technologies, including blogs, wikis, You Tube videos, mobile devices such as phones and tablets, Twitter, Skype and Facebook. Andreas Kaplan and Michael Haenlein (2010) define social media as:

A group of Internet-based applications that ...allow the creation and exchange of usergenerated content, based on interactions among people in which they create, share or exchange information and ideas in virtual communities and networks.

Social media are strongly associated with young people and 'millenials' - in other words, many of the students in post-secondary education. At the time of writing social media are only just being integrated into formal education, and to date their main educational value has been in non-formal education, such as fostering online communities of practice, or around the edges of classroom teaching, such as 'tweets' during lectures or rating of instructors.

\section{A paradigm shift}

It can be seen that education has adopted and adapted technology over a long period of time. There are some useful lessons to be learned from past developments in the use of technology for education, in particular that many claims made for a newly emerging technology are likely to be neither true nor new. Also new technology rarely completely replaces an older technology. Usually the old technology remains, operating within a more specialized 'niche', such as radio, or integrated as part of a richer technology environment, such as video in the Internet.

There are various ways in which such a strategy may be developed (Bates and Sangrà, 2011), including top-down and bottom-up processes for setting overall goals, but in a university it may be through an annual academic planning process where departments/faculties must submit their plans for the next three years, including resources needed, based on meeting 
the overall academic goals set by the university. In such a planning cycle, it is important to include the goals for meeting the needs of learners in a digital age as 'targets' for departments when drawing up their plans. These plans should indicate not only content to be covered but also delivery and teaching methods to be used, with a rationale for them.

However, what distinguishes the digital age from all previous ages is the rapid pace of technology development and our immersion in technology-based activities in our daily lives. Thus it is fair to describe the impact of the Internet on education as a paradigm shift, at least in terms of educational technology. We are still in the process of absorbing and applying the implications.

\section{CONCLUSION}

Based on the explanation above, the writer concludes that computer theories and beliefs about education will influence strongly the choice and use of different technologies. the use of technology for teaching and learning in digital area: Computer-Based Learning, computer networking, Online learning environment, Social Media and a paradigm shift. Therefore, the teachers should empower digital learning platforms as part of their instruction activity to make learning more engaging, interesting, and interactive.

\section{REFERENCES}

Bates, A. and Sangrà, A. (2011) Managing Technology in Higher Education: Strategies for Transforming Teaching and Learning San Francisco: Jossey-Bass/John Wiley \& Co.

Donovan, T. et al. (2019) Tracking Online and Distance Education in Canadian Universities and Colleges: 2019 Canadian National Survey of Online and Distance Education Halifax NS: Canadian Digital Learning Research Association.

Friedman, T. (2005). The world is flat: A brief history of the twenty-first century. New York: Farrar, Straus and Giroux.

Falck, O., Mang, C., \& Woessmann, L. (2018). Virtually No Effect? Different Uses of Classroom Computers and their Effect on Student Achievement. Oxford Bulletin of Economics and Statistics, 80(1), 1-38.

Gasser, U., Cortesi, S. C., Malik, M., \& Lee, A. (2012). Youth and Digital Media: From Credibility to Information Quality. SSRN Electronic Journal, 1-150.

Jones, C. (2015). Theories of Learning in a Digital Age. In: Networked Learning. Research in Networked Learning. Springer, Cham.

Padmavathi, G. (2019). Teaching and Learning in the Digital Age. 3(1), 1-23.

Prensky, M. R. (2012). From Digital Natives to Digital Wisdom: Hopeful Essays for 21st Century Learning. Corwin Press.

University of British Columbia (2014) Flexible Learning - Charting a strategic vision for UBC (Vancouver Campus) Vancouver BC: Flexible Learning Implementation Team 
Volume 1, Number 3, December 2021, Page. 111 - 116

Email : editorijhess@gmail.com

University of Ottawa (2013) Report of the e-Learning Working Group_Ottawa ON: The University of Ottawa 